\title{
p63 deficiency activates a program of cellular senescence and leads to accelerated aging
}

\author{
William M. Keyes, ${ }^{1}$ Ying Wu, ${ }^{1}$ Hannes Vogel, ${ }^{2}$ Xuecui Guo, ${ }^{1}$ Scott W. Lowe, ${ }^{1}$ and Alea A. Mills ${ }^{1,3}$ \\ ${ }^{1}$ Cold Spring Harbor Laboratory, Cold Spring Harbor, New York 11724, USA; ${ }^{2}$ Stanford University, \\ Stanford, California 94305, USA
}

\begin{abstract}
The p53 tumor suppressor plays a key role in organismal aging. A cellular mechanism postulated to drive the aging process is cellular senescence, mediated in part by p53. Although senescent cells accumulate in elderly individuals, most studies have relied on correlating in vitro senescence assays with in vivo phenotypes of aging. Here, using two different mouse models in which the p53-related protein p63 is compromised, we demonstrate that cellular senescence and organismal aging are intimately linked and that these processes are

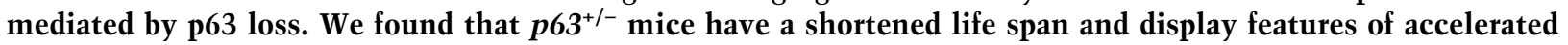
aging. Both germline and somatically induced p63 deficiency activates widespread cellular senescence with enhanced expression of senescent markers SA- $\beta$-gal, PML, and $16^{\mathrm{INK} 4 \mathrm{a}}$. Using an inducible tissue-specific p63 conditional model, we further show that p63 deficiency induces cellular senescence and causes accelerated aging phenotypes in the adult. Our results thus suggest a causative link between cellular senescence and aging in vivo, and demonstrate that $\mathrm{p} 63$ deficiency accelerates this process.
\end{abstract}

[Keywords: Aging; mouse models; p63; senescence]

Supplemental material is available at http://www.genesdev.org.

Received March 5, 2005; revised version accepted July 5, 2005.

Multicellular organisms with renewable tissues have evolved several mechanisms for regulating aberrantly growing cells, most notably apoptosis and senescence (Campisi 2001). Cellular senescence is a form of irreversible growth arrest, originally described for end-stage proliferative cells in culture (Hayflick 1965), but now known to be induced by multiple stimuli including DNA damage, oxidative stress, chemotherapy, and excess mitogenic stimuli such as oncogene activation (Serrano et al. 1997; Campisi 2001; Schmitt et al. 2002). Senescence is controlled by the $\mathrm{p} 53$ and $\mathrm{Rb}$ tumor suppressors, resulting in accumulation of key senescence proteins such as the tumor suppressors $\mathrm{p} 16^{\mathrm{INK} 4 \mathrm{a}}, \mathrm{p} 19^{\mathrm{Arf}}$, and promyelocytic leukemia protein (PML) (Serrano et al. 1997; Ferbeyre et al. 2000; Pearson et al. 2000; Narita et al. 2003; de Stanchina et al. 2004). PML protein is a component of nuclear structures known as nuclear bodies (NBs) that are involved in processes such as senescence, apoptosis, and differentiation (Salomoni and Pandolfi 2002). However, in response to senescence-inducing stimuli, the size and number of PML NBs have been shown to increase in cultured cells (Ferbeyre et al. 2000;

${ }^{3}$ Corresponding author.

E-MAIL mills@cshl.edu; FAX (516) 367-8874.

Article published online ahead of print. Article and publication date are at http://www.genesdev.org/cgi/doi/10.1101/gad.342305.
Pearson et al. 2000). Although mostly studied in vitro, cellular senescence has been correlatively linked to the aging process at the level of the whole animal, thus implicating many of the factors that regulate senescence as contributing to organismal aging (Sharpless and DePinho 2004; Campisi 2005).

In contrast to p53's established role in mediating tumor-suppressive mechanisms such as senescence, the p53-related protein $\mathrm{p} 63$ has until now been attributed mainly a developmental role due to its ability to regulate proliferation, differentiation, and cell fate (Mills et al. 1999; Yang et al. 1999; Koster et al. 2004; Kurita et al. 2004). p63-deficient mice exhibit striking epithelial defects, including complete absence of skin, hair, and many ectodermal derivatives (Mills et al. 1999; Yang et al. 1999). Whereas these loss-of-function studies clearly demonstrated that $\mathrm{p} 63$ is necessary for stratified epithelia to form, gain-of-function studies revealed that p63 is sufficient for dictating epithelial cell fate (Koster et al. 2004). However, in addition to its role in formation of the skin during development, p63 also functions to replenish epithelia of mature skin (Koster et al. 2004) - a cell type that is continually replaced about once every 2 wk in humans. Some reports indicate that p63 is essential for maintaining the stem cell pool, while others suggest it is needed for cell fate decisions (McKeon 2004). Together, these studies highlight the fact that p63 pos- 
sesses roles in differentiation and rejuvenation of epithelia, both during embryonic development and in mature epithelia.

The p63 gene is transcribed from dual promoters, and undergoes alternative splicing to generate multiple transcripts that encode different p63 proteins (Yang et al. 1998). These p63 isoforms can be classified into two major subtypes: those that possess an N-terminal transactivation domain similar to that of p53 and those that lack this domain, referred to as the transactivating (TA) and the dominant-negative (DN) isoforms, respectively. The DN isoforms are the most abundant isoform class in mature proliferating epithelia such as the skin, and expression of these isoforms is dramatically down-regulated during differentiation and growth arrest (Yang et al. 1998; Westfall et al. 2003; Koster et al. 2004). In addition to differences between different p63 isoforms at the $\mathrm{N}$ termini, alternative splicing generates $\alpha, \beta$, and $\gamma$ isoforms for both the TA- and DN-isoform classes, producing six different p63 proteins that could potentially interact with distinct $\mathrm{p} 63$ isoforms and/or additional members of the p53 protein family to generate a myriad of complexes with diverse transcriptional abilities.

Although p63-deficient mouse models generated by us and by others have been extremely informative for uncovering the physiological role of p63 during development, the perinatal lethality of $p 63^{-/-}$mice prevents assessment of p63 function past the neonatal stage (Mills et al. 1999; Yang et al. 1999). Here, we describe a novel p63 conditional mouse model that inactivates all p63 isoforms in an inducible and tissue-specific manner, providing a system for assessing the biological role of p63 in the adult. Using both the $p 63^{-/-}$and the $p 63$ conditional mouse models, we describe two novel roles for p63 in regulating senescence and aging through modulation of p16 $6^{\text {INK4a }}$ and PML, providing in vivo evidence linking these two processes.

\section{Results}

During the course of an extensive study, we noticed that although $\mathrm{p} 3^{+/-}$mice were not susceptible to spontaneous tumors (W.M. Keyes and A.A. Mills, unpubl.), they had a significant reduction in life span (Fig. 1A). Whereas the median life span for wild-type mice $(n=74)$ was 121 wk, that of $p 63^{+/-}$mice $(n=104)$ was only $95 \mathrm{wk}$. This decrease in life span was highly significant $(P<0.0001$, log-rank test), and represented a $21.5 \%$ decrease in longevity. Intriguingly, the decreased longevity of $\mathrm{p}^{63^{+/-}}$ mice was almost identical to that observed for $p 53^{+/ \mathrm{m}}$ mice, a mouse model in which enhanced p53 activity provided resistance to spontaneous tumors while simultaneously accelerating the aging process (Tyner et al. 2002). Some of the $\mathrm{p} 3^{+/-}$cohort died with no signs of malignancy, and others developed life-threatening lesions or appeared sickly, and several features characteristic of age-related decline were noted (Fig. 1B-G; Supple-

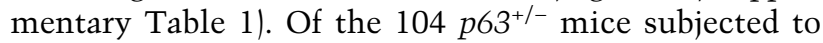
detailed histology, $8 \%(n=8)$ were found dead with no macroscopic or microscopic signs of malignancy. A large
A
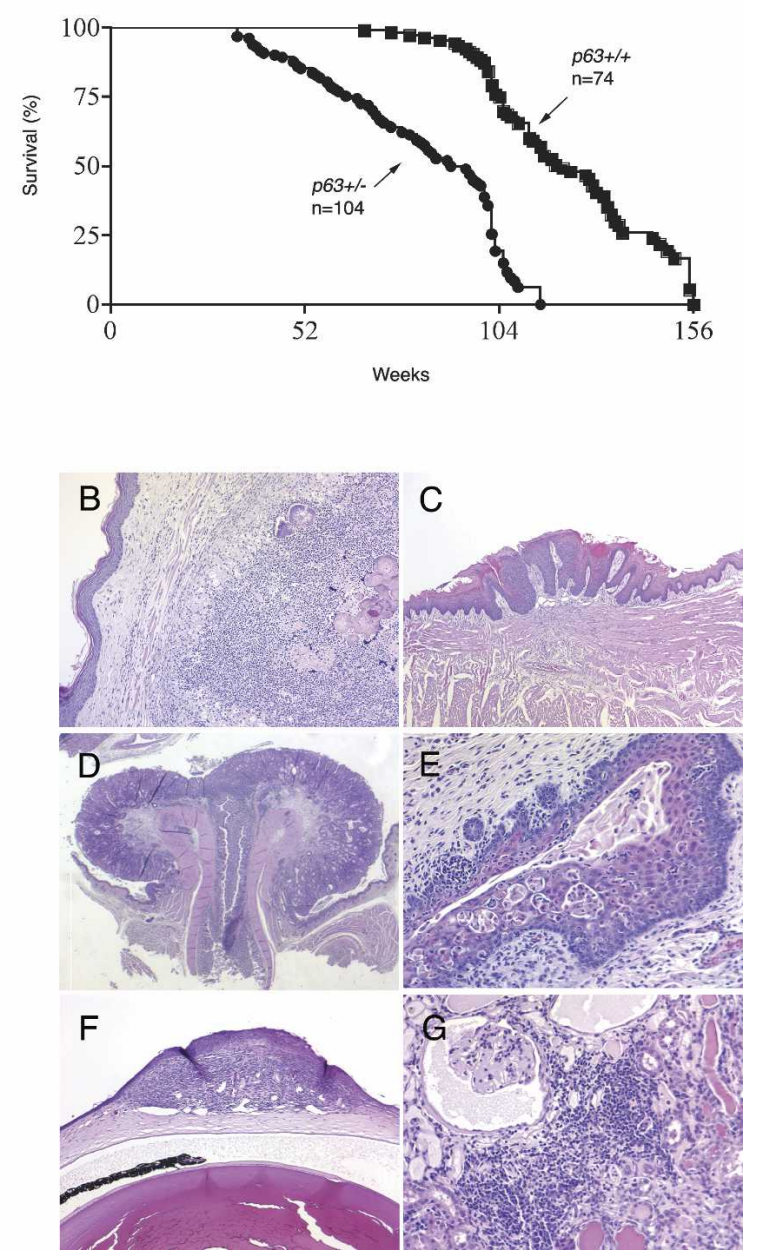

Figure 1. Life span is decreased in $p 63^{+/-}$mice. $(A)$ Over the course of a $>2.2$-yr study, the median life span for wild-type mice $(n=74)$ was $121 \mathrm{wk}$, whereas that of $p 63^{+/-}$mice $(n=104)$ was $95 \mathrm{wk}$, a difference of $21.5 \%(P<0.0001$, log-rank test $)$. $p 63^{+/-}$mice frequently developed hyperplastic lesions in a variety of epithelia. $(B-G)$ Histological analysis of tissues of $p 63^{+/-}$ mice. $(B)$ Dorsal back skin. $(C)$ Dorsal surface of the tongue. $(D)$ Rectum. $(E)$ Vagina. $(F)$ Cornea of the eye. $(G)$ Glomerulus of the kidney.

percentage of this cohort had to be euthanized for one or more of the following reasons: $52 \%(n=54)$ had severe skin lesions or infections, $35 \%(n=36)$ were extremely weak, $19 \%(n=20)$ had palpable lymph nodes, $14 \%$ $(n=14)$ had an enlarged abdomen, $12 \%(n=12)$ had visible signs of hemorrhage, $6 \%(n=6)$ had rectal prolapse, and $2 \%(n=2)$ had an aberrant circling behavior.

Hyperplastic epithelia were common, and skin lesions that often progressed in severity were frequently observed. Histological analysis of biopsies from ulcerated skin showed severe abscesses in the dermis, which often contained bacterial inclusions (Fig. 1B). Many of the $p 63^{+/-}$mice showed evidence of chronic infection of the skin, subcutaneous tissues, oropharynx, and genitourinary tract.

Since p63 is expressed at high levels in proliferating 
cells of stratified epithelia other than that of the skin, we extended our analysis to other epithelial tissues. Indeed, in addition to the defects evident in the epidermis, severe lesions of other epithelia such as that of the tongue, rectum, cervix, and cornea of the eye were observed (Fig. C-F). These defects included acanthosis of epithelia of the tongue, rectal prolapse, vaginal cervicitis, and corneal granulation of the surface of the eye. We were not surprised to find the most severe pathology in p63-expressing tissues. In addition to these defects, we also noticed additional phenotypes in tissues of nonsquamous epithelia. Several mice had chronic nephritis of the kidney - an organ in which p63 is expressed (Fig. 1G; A.A. Mills, unpubl.). Of note was the observation that the kidney pathology observed in $p 63^{+/-}$mice resembles that of the human kidney from patients of advanced age (Rodwell et al. 2004).

Since longevity and fitness were significantly compromised in mice carrying a single disrupted p63 allele that inactivates all p63 isoforms and reduces p63 to haploid levels, we next developed a system that allowed us to study the consequence of somatic p63 loss by generating a $p 63$ conditional model that provided inducible, tissuespecific $p 63$ disruption (Fig. 2A). This approach bypasses the neonatal lethality caused by germline p63 deficiency (Mills et al. 1999; Yang et al. 1999), hence allowing us to investigate the consequence of p63 deficiency in the adult. We had previously used embryonic stem cell technology to generate the $p 63^{\text {flox }}$ mouse model, which harbors a p63 allele with a pair of lox $P$ sites encompassing exons encoding the DNA-binding domain (DBD) (Mills et al. 2002). This region is highly homologous to the DBD of p53, is essential for p63's transcriptional activity, and is shared by all p63 isoforms (Yang et al. 1998). Mice homozygous for the $p 63^{\text {flox }}$ allele were viable, fertile, and did not display any detectable phenotype (Mills et al. 2002). As expected, expression of Cre resulted in removal of exons encoding the majority of the DBD, converting the $p 63^{\text {flox }}$ allele to the $p 63^{\text {Brdm3 }}$-null allele. In contrast to the wild-type phenotype of $p 63^{\text {flox/flox }}$ animals, $p 63^{\text {Brdm } 3 / B r d m 3}$ embryos were phenotypically similar to the $p 63^{-/-}$embryos that we characterized previously (Mills et al. 1999, 2002).

To establish a system for disrupting $p 63$ in vivo, we crossed the $p 63^{\text {flox }}$ strain to the K5CrePR 1 mouse strain (Fig. 2A), which harbors a transgene that uses the keratin 5 (K5) promoter to express mifepristone-inducible Cre within proliferating keratinocytes of stratified epithelia such as the skin in a pattern that overlaps that of endogenous p63 (Mills et al. 1999; Yang et al. 1999; Zhou et al. 2002). Crosses between mice with the appropriate $p 63^{\text {flox }}$ and K5CrePR 1 alleles produced a subset of progeny that were homozygous for the $p 63^{\text {flox }}$ allele that also had the inducible Cre transgene (Fig. 2B, lane 6). In some cases, p63 ${ }^{\mathrm{Brdm} 2}$ mice that carry a null $p 63$ allele (Mills et al. 1999) were included in the mating scheme so that p63 flox/Brdm2; K5CrePR1 progeny were generated (Fig. 2B, lane 5). p63 flox/flox; K5CrePR1 and p63 flox/Brdm2; K5CrePR1 progeny (referred to as "p63 ablated" after Cre-mediated p63 disruption) and sibling controls of a variety of genotypes that would not facilitate $p 63$ nullizygosity (referred to as "controls"; e.g., Fig. 2B, lanes 1-4) were generated, and Cre was activated in utero or after birth by treatment with mifepristone. Cre-mediated excision of exons encoding the DBD occurred in p63ablated progeny, but not in sibling controls that were also exposed to inducer (data not shown). Importantly, this system inactivates all six p63 isoforms that have been described since DBD-encoding exons excised by Cre are common to all p63 proteins (Yang et al. 1999; Mills et al. 2002). Indeed, Western analyses revealed that $\mathrm{DNp} 63 \alpha$, the predominant p63 isoform expressed in mature skin, is efficiently ablated in response to mifepristone treatment in p63-ablated, but not in control skin (Fig. 2C). Similarly, immunofluorescent analyses demonstrated that the number of p63-positive cells was dramatically reduced in response to Cre activation in p63ablated skin, relative to that of controls (Fig. 2D). These analyses demonstrate that the $p 63$ conditional model provides efficient disruption of the $p 63$ locus, hence inactivating $\mathrm{p} 63$ in vivo.

To evaluate whether the $p 63$ conditional model could be used to generate progeny that phenocopied p63-deficient embryos generated by germline p63 deficiency, we next activated Cre in utero by administration of mifepristone during midgestation. Microscopic examination of control, $p 63^{-1-}$, and p63-ablated progeny at the wholemount level revealed that p63 ablation induced in utero caused a phenotype that was similar to that of $p 63^{-/-}$ mice (Fig. 3A). Indeed, somatic p63 ablation in stratified epithelia caused dramatic developmental defects of the limbs, skin, and facial region that are characteristic of germline p63 deficiency (Mills et al. 1999; Yang et al. 1999). Histological analysis of the skin of p63-ablated embryos demonstrated that whereas the epidermis was stratified in control skin, it was devoid of stratified structure in p63-ablated skin (Fig. 3B). To evaluate the extent of defects in epidermal morphogenesis imposed by p63 deficiency, we used immunofluorescence to examine the expression pattern of markers of distinct stages of epidermal differentiation in control and p63-ablated skin (Fig. 3B). Although the proliferating keratinocyte marker keratin 14 (K14) was expressed robustly in control skin, it was not detectable in p63-ablated tissue, indicating that $\mathrm{p} 63$ deficiency correlated with a lack of proliferating epidermal cells. Similarly, early-stage epidermal markers keratins 1 and $10(\mathrm{~K} 1 / 10)$, as well as the late-stage epidermal marker fillaggrin, were expressed in control skin, but as in $p 63^{-/-}$skin (Mills et al. 1999), these markers were not detectable in p63-ablated skin (Fig. 3B). Thus, these analyses demonstrate that ablation of p63 can generate embryos that have a similar phenotype to that of p63 ${ }^{-/-}$embryos in which the program of epidermal morphogenesis has been arrested.

Given the decrease in life span and compromised fitness of mice with haploid levels of p63, combined with the finding that morphogenesis is arrested in p63-deficient embryos, we asked whether cellular senescence caused by compromised p63 function might be an underlying cellular mechanism for age-related decline at the 
A K5CrePR1
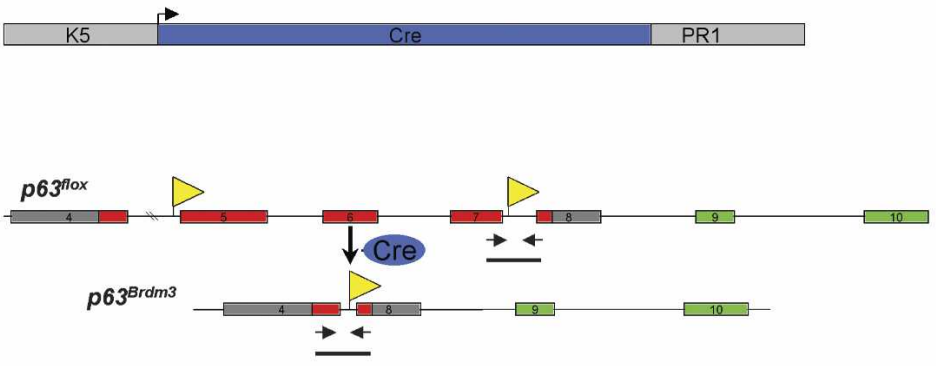

B
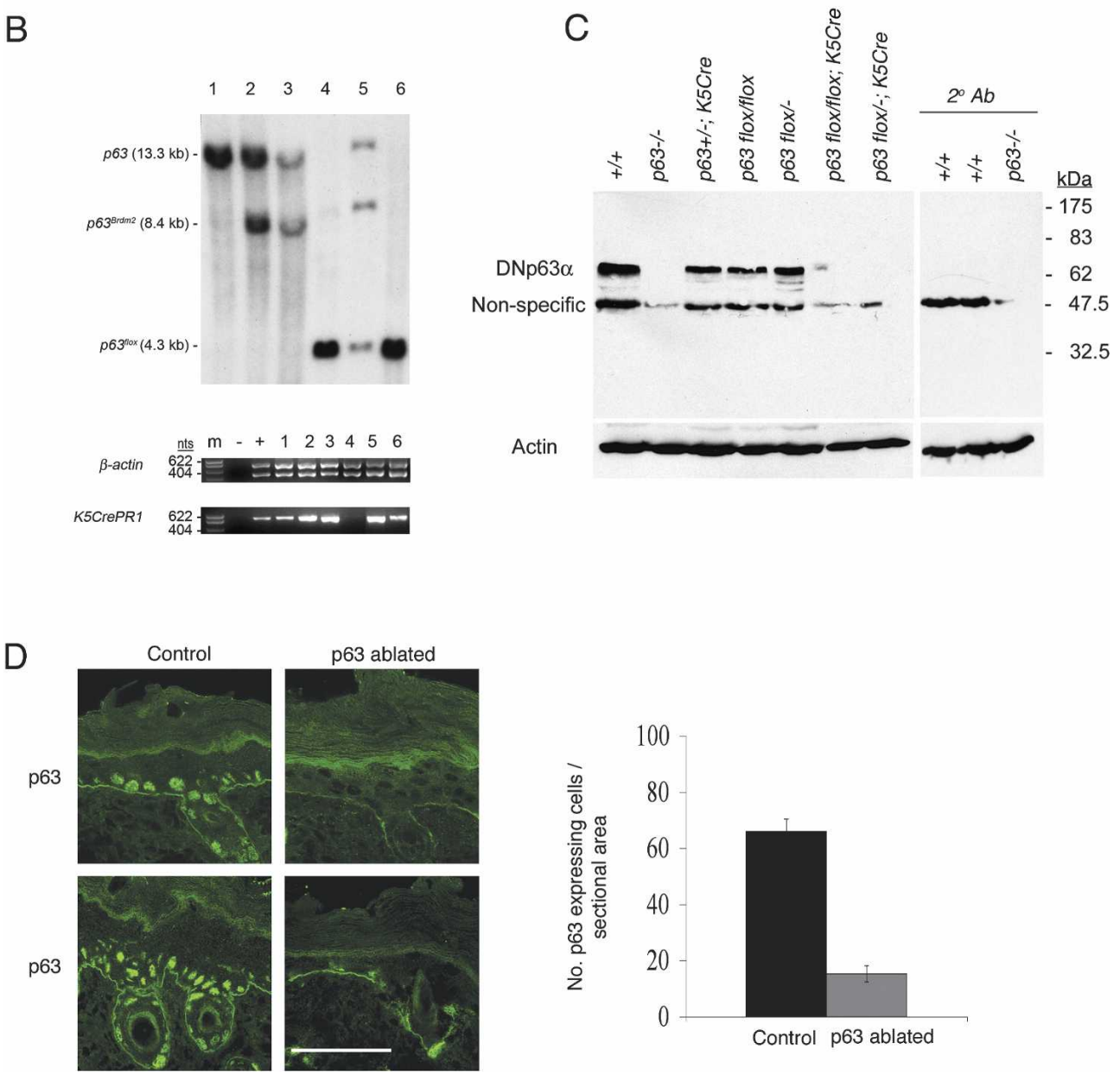

Figure 2. Inducible, tissue-specific Cre-mediated $p 63$ disruption in vivo. (A) Schematic diagram of the $K 5$ CrePR 1 and $p 63^{f l o x}$ alleles used to generate the p63 conditional system. The K5CrePR 1 transgene uses the K5 promoter to drive expression of the Cre-progesterone receptor fusion protein, which provides expression of an inducible form of Cre specifically within stratified epithelia such as the skin. The $p 63^{\text {flox }}$ allele contains a pair of loxP sites (yellow triangles) encompassing the majority of the DBD (red). Excision of DBD-encoding exons by Cre disrupts $p 63$, alters the reading frame of any potential p63 transcript, and inactivates all p63 isoforms. $p 63^{f l o x}$ and $p 63^{\text {Brdm3 }}$ (disrupted) alleles were identified by amplifying the unique junctions using the PCR primers shown (arrows). ( $B$, top) Southern blot hybridization of DNA samples from E17.5 embryos showing endogenous (p63), null (p63 ${ }^{\text {Brdm2 }}$ ), and floxed (p63 $\left.{ }^{\text {flox }}\right)$ p63 alleles. (Bottom) PCR was used to amplify $\beta$-actin as a positive control and the K5CrePR1 transgene from the same templates analyzed above. $p 63^{\text {flox } / \text { Brdm2 }}$; K5CrePR1 (lane 5) and p63 flox/flox $;$ K5CrePR1 (lane 6) have the correct genotype to facilitate Cre-mediated p63 disruption in response to mifepristone treatment. $(C)$ Western blot analyses of lysates prepared from dorsal back skin biopsies obtained from E17.5 wild-type and $p 63^{-/-}$embryos, as well as from embryos that had been treated with mifepristone at E10.5. DNp63 $\alpha$, the predominant p63 isoform in mature epidermis, is efficiently ablated in utero. $(D)$ p63 immunofluorescence and quantitation of p63-expressing cells from post-natal day 4 (P4) dorsal back skin from control (p63 $3_{\text {Brdm2/flox })}$ and p63-ablated (p63 flox/Brdm2; K5CrePR1) mice after treatment with inducer at P2. Quantitation of proliferating cells was evaluated by counting the number of fluorescently labeled cells per total number of cells in both the interfollicular and follicular epidermis. Bar, $100 \mu \mathrm{M}$. 
A
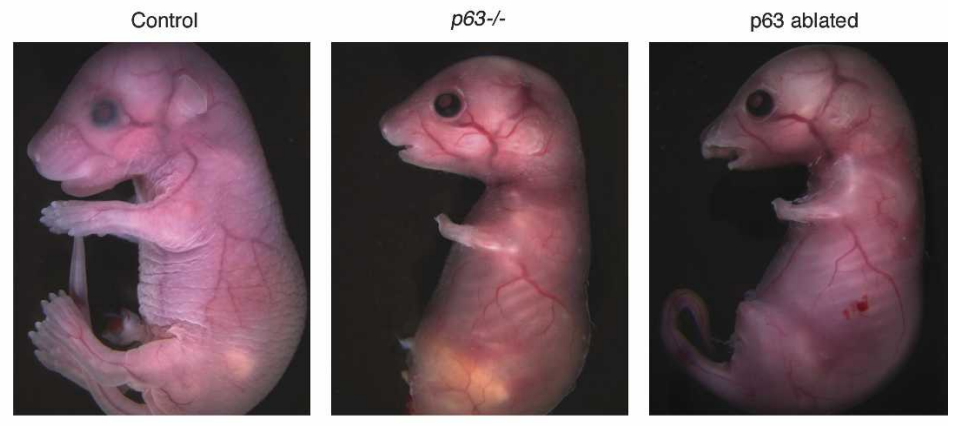

B

Figure 3. Cre-mediated $p 63$ disruption induced by mifepristone treatment efficiently ablates p63 in utero. (A) Whole-mount microscopy of control, $p 63^{-/-}$, and p63-ablated embryos at E17.5 demonstrates that p63-ablated mice have a phenotype similar to that of $p 63^{-/-}$embryos. Note that the p63-ablated embryo shown was generated by administration of mifepristone at E8.5, and the embryo was allowed to develop until harvest at E17.5. (B) Skin biopsies from control and p63-ablated embryos similar to those shown in $A$ were examined by histological and immunofluorescent analyses. Epidermal morphogenesis was halted in response to Cre-mediated p63 ablation induced by mifepristone treatment at E8.5, as seen by the lack of stratification by histological analysis $(\mathrm{H} \& \mathrm{E})$ and by the absence of expression of proliferating (K14), early-stage (K1/K10), and late-stage (fillaggrin) epidermal markers by immunofluorescence in p63-ablated skin. Bar, $10 \mu \mathrm{M}$.

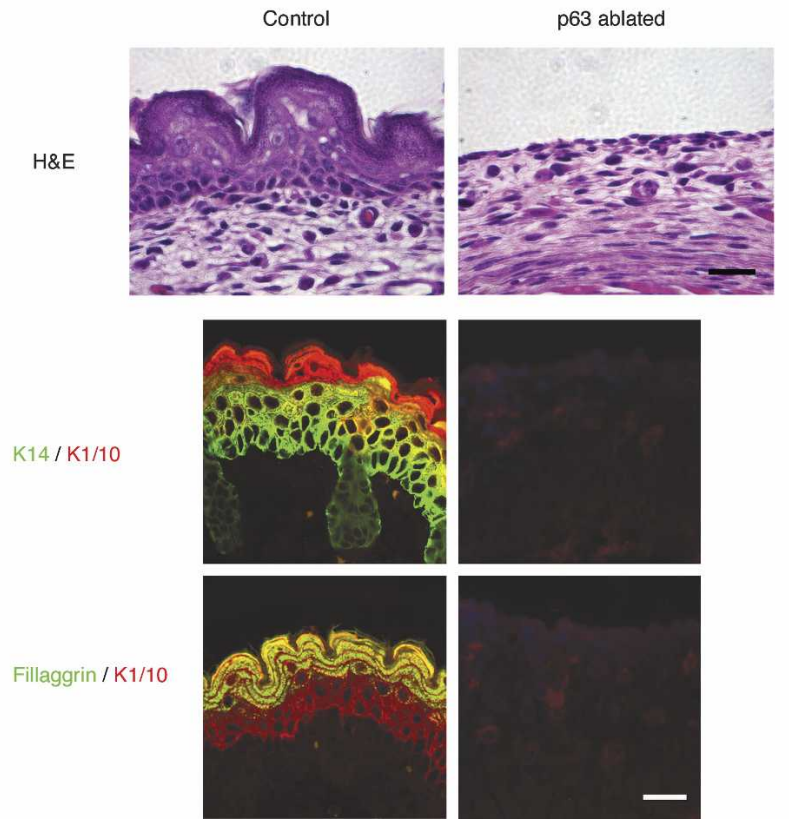

organismal level. To investigate whether p63 deficiency enhanced senescence in vivo, we examined the degree of senescence in response to both germline and somatic p63 deficiency by assaying for endogenous senescence-associated $\beta$-galactosidase (SA- $\beta$-gal) activity, an established marker of cellular senescence (Dimri et al. 1995). When SA- $\beta$-gal activity was assessed at the whole-mount level, we found that control late-stage embryos had very low levels of endogenous SA- $\beta$-gal activity, whereas both $p 63^{-/-}$and p63-ablated embryos expressed high levels of this senescence marker (Fig. 4A). Histological analysis of skin sections from these SA- $\beta$-gal assayed embryos revealed that both $p 63^{-/-}$and p63-ablated skin have an increase in the number of senescent cells relative to that of control tissue (Fig. 4A). To ensure that the intense staining for SA- $\beta$-gal activity was not simply an artifact of the whole-mount procedure, we next analyzed for SA$\beta$-gal activity in skin biopsies by first preparing frozen sections of the skin, and subsequently performing the SA- $\beta$-gal assay in situ (Fig. 4B). Consistent with the results obtained using the whole-mount procedure, skin from control embryos was stratified and essentially devoid of endogenous SA- $\beta$-gal activity. In contrast, widespread senescence was detected throughout the undeveloped surface of $p 63^{-/-}$skin, with an intense focal distribution of SA- $\beta$-gal-positive cells in p63-ablated skin. The different patterns of senescence observed in $p 63^{-/-}$and p63-ablated skin likely reflects the differentiation stage at which $p 63$ deficiency occurred in the two systems. Epithelia of $p 63^{-/-}$embryos do not express p63, and therefore morphogenesis of stratified epithelia does not progress past the undifferentiated ectodermal stage. In contrast, p63 is initially expressed normally in the single layered ectoderm of $p 63^{\text {flox/flox }}$; K5CrePR1 embryos. TAp63 isoforms are the predominant isoforms expressed in the undifferentiated ectoderm, and these $\mathrm{p} 63$ proteins are detectable at embryonic day 7.5 (E7.5) and mediate initiation of the stratification program (Koster et al. 2004). When Cre is induced at E8.5, the ectoderm has already begun to differentiate, but has not yet stratified. Therefore, p63 deficiency that is induced after epithelial morphogenesis has initiated causes a different pattern of 
A

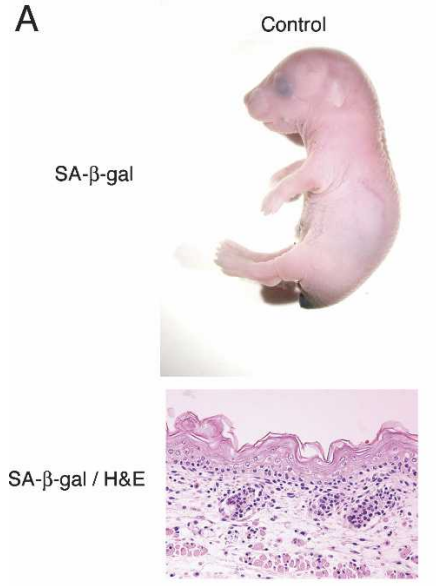

B
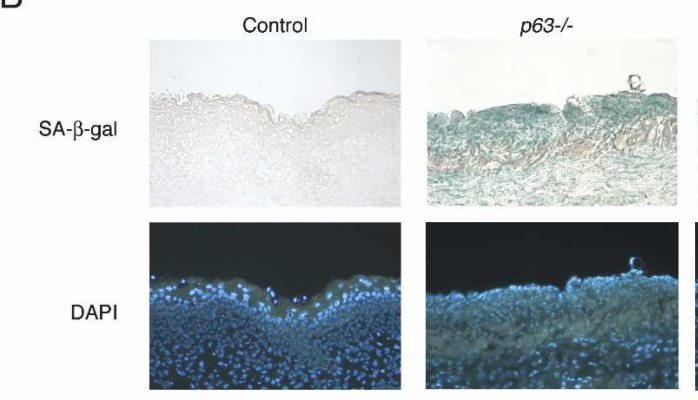

C
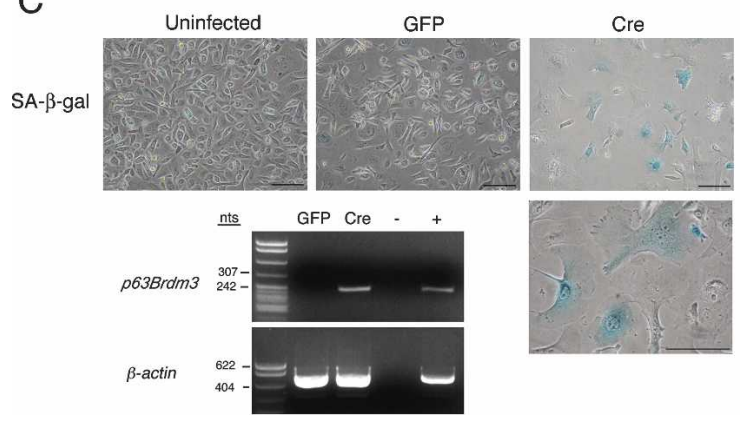
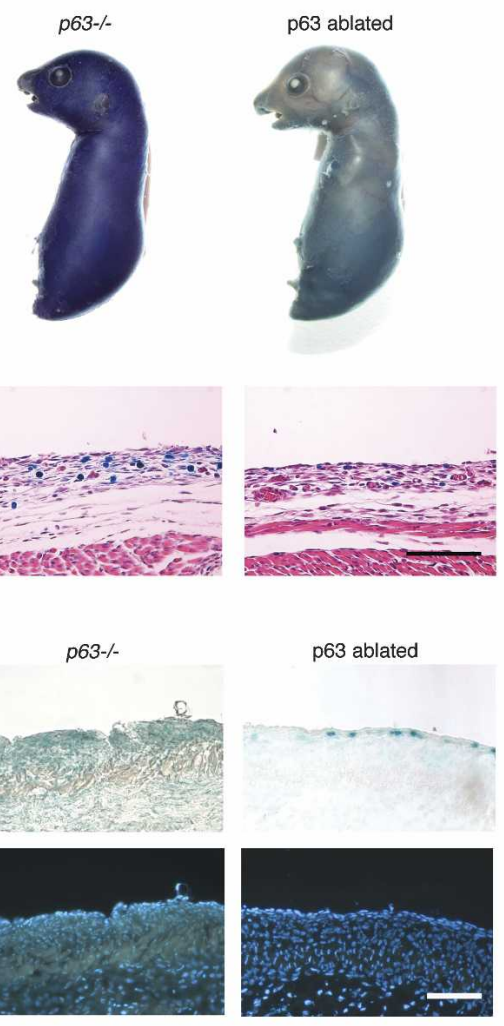

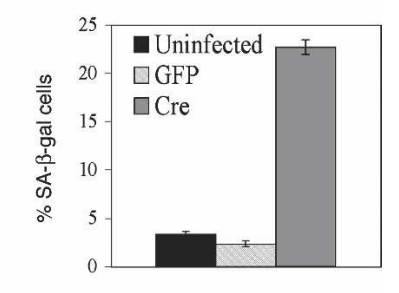

Figure 4. The senescence marker SA- $\beta$ $\mathrm{gal}$ is induced in response to both germline and somatically induced p63 deficiency in vivo, and in primary keratinocytes in culture. (A) A whole-mount assay for endogenous SA- $\beta$-gal activity was performed on E17.5 $p 63^{+/+}, p 63^{-/-}$, and p63-ablated embryos; skin sections from SA- $\beta$-gal assayed embryos were subjected to histological analysis; the intense blue color observed in $p 63^{-/-}$embryos is indicative of senescent cells. Bar, $100 \mu \mathrm{M}$. (B) Dorsal back skin biopsies from E17.5 control, $p 63^{-/-}$, and p63-ablated embryos (treated with mifepristone at E8.5) were stained with Dapi to show histology (bottom panels) and assayed for endogenous SA- $\beta$-gal activity (top panels). Positive (blue) cells were essentially undetectable in control skin, whereas $p 63^{-/-}$and p63-ablated skin had a dramatic increase in cellular senescence. Bar, $100 \mu \mathrm{M}$. (C) Primary keratinocyte cultures from $p 63^{\text {flox/flox }}$ mice were uninfected, or infected with GFP-expressing (GFP) or Cre-expressing (Cre) retrovirus. DNA prepared from these cultures was subjected to PCR to identify the disrupted $p 63^{\text {Brdm3 }}$ allele. $\beta$-Actin was used as a positive control. Cultures were subjected to the SA- $\beta$-gal assay, and senescent cells were quantitated. Bar, $100 \mu \mathrm{m}$. cellular senescence than does germline p63 deficiency in which the ectoderm never commits to the stratified lineage. Thus, senescence occurs in response to both germline and somatically induced p63 deficiency in vivo.

To evaluate whether senescence induced by p 63 deficiency in the embryo could also be observed at the cellular level, we investigated the consequence of p63 ablation in primary keratinocytes, a cell type in which p63 is expressed robustly. Primary keratinocyte cultures were first established from $p 63^{\text {flox/flox }}$ neonates, and $p 63$ was disrupted by infecting the cultures with retroviral Cre (Fig. 4C). Parallel cultures were either uninfected or infected with green fluorescent protein (GFP)-expressing retrovirus. To assay these keratinocytes for Cre-mediated excision of exons encoding the DBD, we prepared genomic DNA and performed PCR using primers specific for the $p 63^{\text {Brdm3 }}$ allele (see Fig. 2A). Excision of DBD-encoding exons was undetectable in control cultures but was efficient in Cre-infected cultures (Fig. 4C).
To correlate $p 63$ disruption with the extent of cellular senescence, keratinocytes were assayed for endogenous SA- $\beta$-gal activity, and the percentage of SA- $\beta$-gal positive cells per total number of cells in each culture was assessed (Fig. 4C). Senescence was induced in Cre-infected cultures but not in control cultures: p63-ablated cells ceased proliferating, became flattened and enlarged, and expressed high levels of endogenous SA- $\beta$-gal (Fig. 4C). The number of senescent cells in uninfected versus p63ablated cells represented an $\sim 10$-fold increase. In contrast, parallel experiments in which wild-type primary keratinocyte cultures that had been infected with retroviral Cre were subjected to the SA- $\beta$-gal assay did not have an appreciable increase in the percentage of senescent cells over background levels (data not shown), demonstrating that senescence is due to p63 loss as opposed to being an effect of Cre toxicity (Loonstra et al. 2001), consistent with the lack of senescence in control embryos that carried the K5CrePR1 transgene but lacked 
the p63 alleles required for complete p63 ablation (data not shown). Together, these results demonstrate that as in p63-deficient skin in vivo, p63 deficiency induces cellular senescence in primary keratinocytes in vitro, consistent with the idea that cellular senescence is a cellautonomous effect in this setting.

Senescent cells have withdrawn from the cell cycle, and therefore induction of cellular senescence correlates with decreased proliferative potential. To examine proliferation in control and p63-deficient skin, timed matings between $\mathrm{p} 63^{+/-}$mice were performed, and embryos were subjected to an in utero bromodeoxyuridine pulse to label proliferating cells (Fig. 5A). Embryos were harvested, skin sections were prepared, and cells that had incorporated BrdU at the time of the pulse (i.e., cells in S-phase) were identified by immunofluorescence. Quantitation of proliferating cells revealed that p 63 deficiency caused a significant (approximately threefold; $P<0.001$ ) reduction in the number of proliferating cells in vivo, a finding consistent with the observation that p63 deficiency causes cellular senescence.

Key mediators and inducers of senescence in vitro are p53, p16 ${ }^{\mathrm{INK} 4 \mathrm{a}}$, and PML (Ferbeyre et al. 2000; Pearson et al. 2000; Narita et al. 2003). To assess whether p63 deficiency evokes similar pathways, we evaluated the pattern of expression of these senescence mediators by immunofluorescence (Fig. 5B). Whereas control skin had a restricted pattern of PML expression, there was increased expression of PML in both $p 63^{-/-}$and p63-ablated skin. Importantly, given PML's role in senescence, immunofluorescence revealed that both the size and number of PML bodies were increased in p63-deficient skin, and multiple PML isoforms were induced by $\mathrm{p} 63$ deficiency, with somatic p63 deficiency appearing to have an enhanced effect (Fig. 5B,C). When we evaluated PML expression at the transcript level, we did not detect an increase in PML expression in p63-deficient skin, suggesting that PML levels are being modified post-transcriptionally (Fig. 5C). p16 $6^{\mathrm{INK} 4 \mathrm{a}}$ was undetectable in control skin, but was increased in a pattern similar to that observed for endogenous SA- $\beta$-gal activity in both $p 63^{-/-}$ and p63-ablated skin (cf. Figs. 4A,B and 5B). We found that not all p63-compromised embryos expressed equivalent levels of $\mathrm{p} 16^{\mathrm{INK} 4 \mathrm{a}}$ at the protein (Fig. 5B) or tran-

A

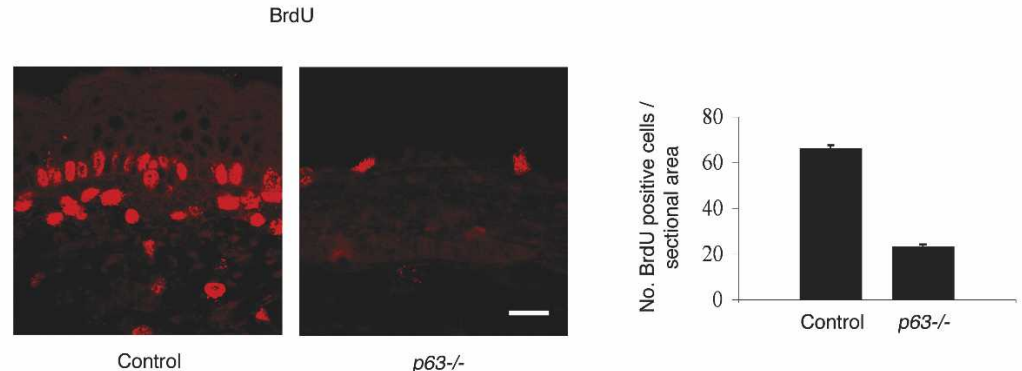

B

Figure 5. Key mediators of cellular senescence are induced in response to p63 deficiency in utero. $(A)$ In vivo proliferation was assessed in E17.5 embryos using the BrdU incorporation assay. After an in utero pulse with BrdU, embryos were harvested and dorsal back skin biopsies from $p 63^{+/+}$(Control) and $p 63^{-/-}$embryos were subjected to immunofluorescent analysis to detect cells that incorporated BrdU. (Right) Proliferating cells were quantitated, showing that p63 deficiency causes decreased proliferation in vivo ${ }_{ \pm} \mathrm{SEM}$; $P<0.001)$. Bar, $10 \mu \mathrm{m}$. (B) Immunofluorescence for PML and $\mathrm{p} 16^{\mathrm{INK} 4 \mathrm{a}}$ in $\mathrm{p} 63^{+/+}$, $p 63^{-/-}$, and p63-ablated embryonic skin at E17.5. Bars represent $10 \mu \mathrm{m}$ for $\mathrm{p} 16^{\mathrm{INK} 4 \mathrm{a}}$ and $50 \mu \mathrm{m}$ for PML. (C) Western blot analysis for PML in representative $p 63^{+/+}$ $(\mathrm{wt}), p 63^{-/-}(-/-)$, and p63-ablated (ab) skin lysates. Real-time PCR analysis was used to determine PML and $\mathrm{p} 16^{\mathrm{INK} 4 \mathrm{a}}$ expression at the transcript level.
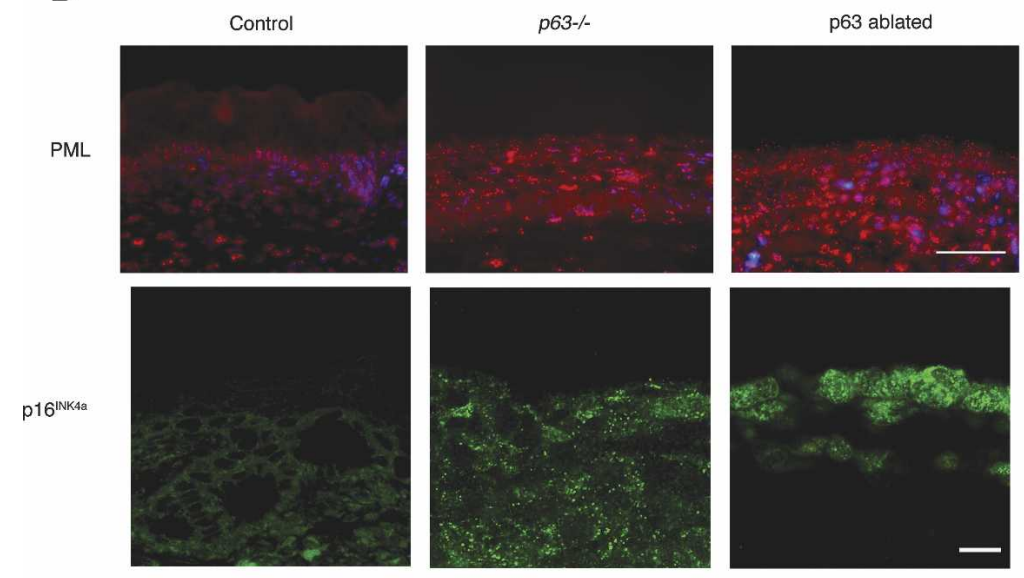

C
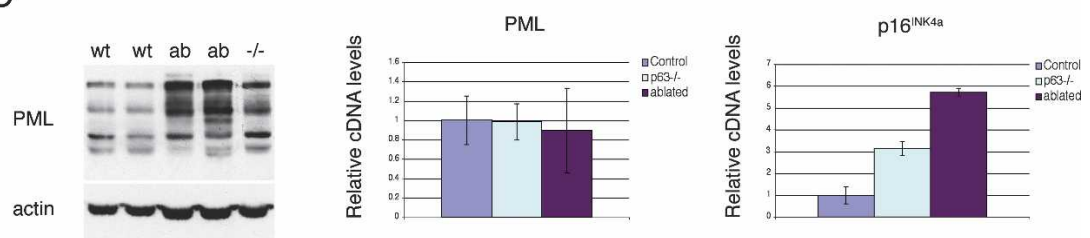
script level (Fig. 5C), suggesting that up-regulation of p $16^{\text {INK4a }}$ in response to p63 deficiency is a transient event that peaks at a specific developmental time point. In contrast to the increased expression of PML and p $16^{\text {INK4a }}$, we were unable to detect any change in $\mathrm{p} 53$ expression in p63-compromised skin (data not shown), even though enhanced p53 expression has been shown to correlate with cellular senescence in some experimental settings (Campisi 2001). To evaluate whether senescence induced by p63 deficiency required p53, we intercrossed mice carrying inactivated p63 and p53 alleles and assayed $p 63^{-/-} ; p 53^{-/}$embryos for SA- $\beta$-gal activity (Supplementary Fig. 1). Using the whole-mount assay described above, we found that $p 63^{-/-} ;$p53 $3^{-/-}$embryos expressed SA- $\beta$-gal in a pattern similar to $p 63^{-/-}$embryos, indicating that senescence induced in response to germline p63 deficiency is p53-independent in vivo. Thus, we demonstrate that senescence induced by p63 deficiency causes enhanced expression of several key senescence mediators in embryonic skin in vivo.

Cellular senescence has been correlatively linked as a causative factor in organismal aging. To investigate whether the effect of p63 ablation on senescence observed in the embryo and in cultured cells would also lead to senescence in the adult, we used the p63 conditional system to examine the effect of p63 ablation in adult skin in vivo. Mice with the appropriate combination of alleles to facilitate Cre-mediated recombination were generated as described above. p63-ablated and ageand sex-matched sibling controls were treated with mifepristone at $8 \mathrm{mo}$ of age (Fig. 6). Whereas control mice carrying the K5CrePR 1 transgene did not develop any detectable phenotype in response to Cre activation even though Cre toxicity has been noted in some experimental settings (Loonstra et al. 2001), p63-ablated mice displayed striking age-associated phenotypes (Fig. 6A; Supplementary Table 1). Some aging features such as alopecia can first be noticed around 1 mo of age even prior to induction, suggesting that expression of Cre can occur in the absence of inducer, and these phenotypes progress in severity over time. p63 deficiency in the adult caused severe alopecia, defects of the skin, and pronounced lordokyphosis, an age-related curvature of the spine that becomes more severe in p63-ablated mice as they age

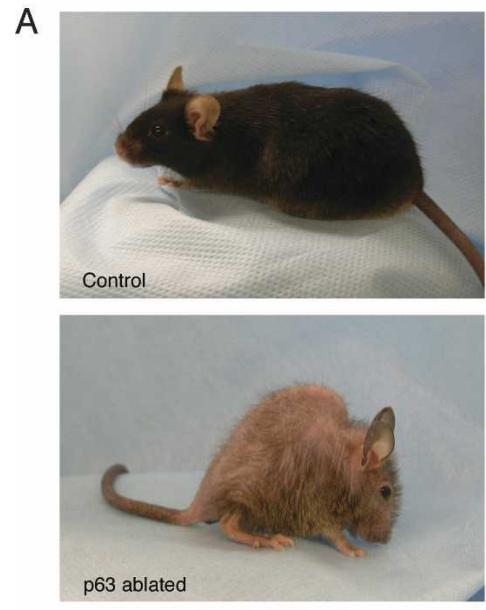

B

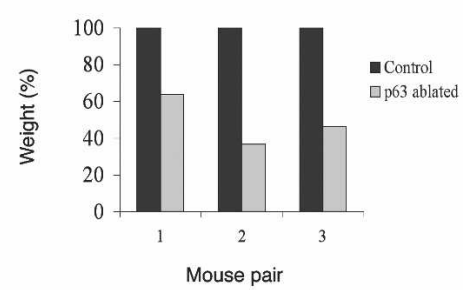

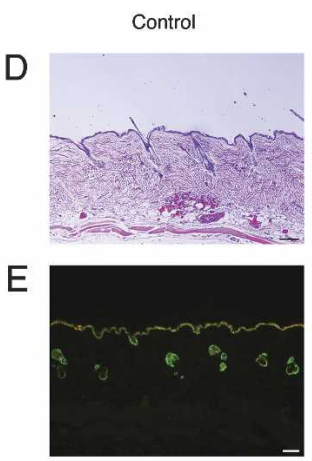

F

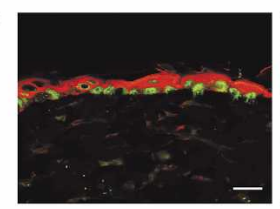

$\mathrm{G}$

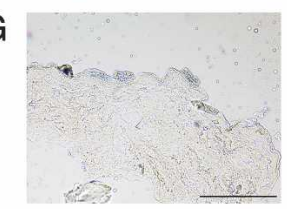

$\mathrm{H}$

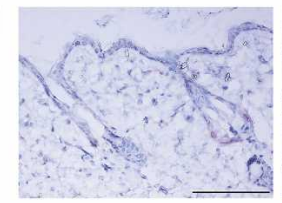

p63 ablated
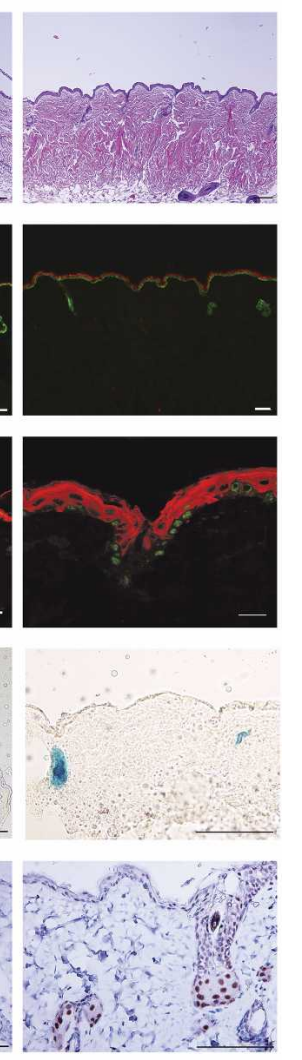

Figure 6. Aging features and senescenceassociated markers are induced in response to p63 deficiency in adult mice. $(A)$ Cre-mediated ablation of $\mathrm{p} 63$ in vivo in control (top panel) and ablated (bottom panel) adult mice at 8 mo of age. Note the pronounced lordokyphosis and alopecia caused by p63 deficiency. (B) Weight of age- and sex-matched sibling pairs of control and p63-ablated adult mice at 7,20, and 22 mo of age, expressed as a percentage of control. $(C)$ The tissue specificity of Cre-mediated $p 63$ disruption in adult control (c), ablated (a) mice was evaluated by PCR amplification of the $p 63^{\text {flox }}$ and $p 63^{\text {Brdm3 }}$ alleles from genomic DNA obtained from different tissues. (Sk) Skin; (To) tongue; (Fs) forestomach; (Th) thymus; (Mu) muscle; (Lu) lung; (Li) liver; (Ki) kidney; (Re) reproductive tract (female); (Bf) brown fat; (Sp) spleen; $(\mathrm{He})$ heart; $(\mathrm{Br})$ brain; (m) BstEII-digested $\lambda$ DNA; (-) negative water control; $(+)$ genomic DNA from a $p 63^{\text {Brdm } 3 /+}$ mouse. $(D-G)$ Dorsal back skin sections of control and p63-ablated 8-mo-old mice, showing the pronounced aging-associated features in the skin of p63-ablated mice. (D) Hematoxylin and eosin staining. (E) K14 (green) and K1/K10 (red). (F) p63 (green) and K1/K10 (red). (G) SA- $\beta$-gal activity. $(H)$ p $16^{\mathrm{INK} 4 \mathrm{a}}$ expression. Bars: $D, E, G, H, 100 \mu \mathrm{m} ; F, 10 \mu \mathrm{m}$. 
(Fig. 6A). In addition to the age-related features evident in the skin and its associated structures, p63-ablated mice had substantial weight loss as compared with ageand sex-matched sibling controls (Fig. 6B).

To investigate whether Cre-mediated p63 disruption was limited to specific tissues or was occurring globally, multiple tissues were harvested from 20-mo-old female control $\left(p 63^{\text {flox } /+}\right)$ and p63-ablated (p63 ${ }^{\text {Brdm2/flox }}$; K5CrePR1) siblings that had been induced at $9 \mathrm{mo}$ of age. Genomic DNA was harvested from a panel of 13 tissues, and a PCR assay was performed that could differentiate between $p 63^{\text {flox }}$ ("wild type") and $p 63^{\text {Brdm3 }}$ (disrupted) alleles (Fig. 6C; see also Fig. 2A). Whereas the $p 63^{\text {flox }}$ allele was detected in all tissues, the disrupted $p 63^{\text {Brdm3 }}$ allele was detected in a tissue-specific manner. Cre-mediated excision of the DBD-encoding exons was readily detectable in tissues from ablated mice that express K5 such as skin, tongue, forestomach, and thymus, in agreement with the ability of the K5 promoter to drive Cre expression in these tissues. In contrast, p63 disruption was not detected in other tissues such as brain and heart that do not express endogenous K5. Other tissues in which Cre-mediated p63 disruption was detected were muscle and lung. Although this was initially unexpected, a previous study reporting a lung phenotype in a transgenic mouse model that used the K5 promoter to drive transgene expression (Carraresi et al. 2001) and the report that $\mathrm{K} 5$ colocalizes with the muscle-specific protein desmin (Hirako et al. 2003) make it likely that these tissues express endogenous K5 and therefore that this promoter is activating Cre and disrupting p63 in these tissues. The PCR amplification product specific for $p 63^{\text {Brdm3 }}$ was not detected in any of the tissues analyzed from control mice that had also been exposed to inducer. These analyses indicate that Cre-mediated disruption of p63 occurs tissue-specifically and is robust in stratified epithelia such as the skin.

Histological analysis revealed that the number of hair follicles was decreased in response to p63 ablation (Fig. 6D). Immunofluorescent analyses demonstrated that $\mathrm{K} 14$ and $\mathrm{K} 1 / \mathrm{K} 10$ were expressed in adult skin, demonstrating that the overall integrity of the skin is maintained even when $p 63$ was inactivated within specific cells (Fig. 6E). To evaluate the extent of p63 ablation in response to Cre activation, skin from control and p63ablated adult mice were costained for expression of $\mathrm{p} 63$ and $\mathrm{K} 1 / \mathrm{K} 10$ (Fig. 6F). The decrease in p63 nuclear expression demonstrated that p63 is efficiently ablated in a subset of keratinocytes in adult epidermis, indicating that Cre-mediated p63 disruption has occurred.

Given the striking age-associated phenotypes observed in p63-compromised mice, coupled with the dramatic increase in cellular senescence observed in response to p63 deficiency both in vitro and in vivo, we next analyzed p63-ablated adult skin for senescence. Consistent with our previous results in embryonic skin, SA- $\beta$-gal activity was essentially undetectable in control skin, but was induced in adult skin in response to p63 ablation (Fig. 6G). To examine whether other proteins implicated in cellular senescence were simultaneously induced in response to p63 deficiency, we examined the pattern of expression of $\mathrm{p} 16^{\mathrm{INK} 4 \mathrm{a}}$. While $\mathrm{p} 16^{\mathrm{INK} 4 \mathrm{a}}$ expression was essentially undetectable in control skin, it was dramatically induced in both the interfollicular epidermis and in the hyperplastic sebaceous glands in p63-ablated skin of the adult, indicating that as in p63-deficient skin of the embryo, p63 deficiency in the adult induces cellular senescence (Fig. 6H; Sharpless and DePinho 2004; Campisi 2005). Interestingly, SA- $\beta$-gal $/ \mathrm{p} 16^{\mathrm{INK} 4 \mathrm{a}}$-positive cells were located at the hair follicle/sebaceous gland junction, the location of the stem cell niche (Fuchs and Raghavan 2002). Taken together, these studies indicate that p63 deficiency induced in squamous epithelia of adult mice causes enhanced cellular senescence and accelerated aging in vivo.

To explore whether the senescence mediators p53, p16 ${ }^{\text {INK4a }}$, and PML would affect the senescent phenotype induced by p63 deficiency, we used RNAi technology to knock down expression of these proteins in primary keratinocytes while simultaneously inducing p63 ablation. Real-time PCR and Western analyses demonstrated that $p 63^{\text {flox/flox }}$ cultures infected with a control GFP-expressing vector retained p63 expression, whereas Cre-infected cultures had reduced p63 expression at both the transcript and protein level (Fig. 7A,B). While an increase in TAp63 transcripts was noted (Fig. 7A), likely due to the fact that primers used for this analysis were specific to exons 2 and 3 , which remain intact in the disrupted p63 ${ }^{\text {Brdm3 }}$ allele, all detectable p63 isoforms appear to be depleted at the protein level (Fig. 7B). It is therefore unlikely that the detectable TA transcript encodes functional TA isoforms since the DBD has been excised and any truncated protein would be out of frame. In addition, p63 protein was not detected by Western analyses even though this p63 antibody was generated against an epitope within exon 4 that should recognize all truncated p63 proteins. Whereas very few senescent cells were detected in control cultures, Cre-infected cultures became senescent (Fig. 7C). To determine whether exogenous expression of $\mathrm{DNp} 63 \alpha$, the predominant isoform expressed in proliferating keratinocytes, could prevent the senescent phenotype induced by p63 deficiency, parallel cultures were infected with Cre- and DNp63 $\alpha$-expressing constructs simultaneously. Although robust DNp63 $\alpha$ expression was attained (Fig. 7C, upper right), these cultures still became senescent, demonstrating that $\mathrm{DNp} 63 \alpha$ alone is not sufficient for preventing senescence caused by net ablation of p63 (Fig. 7C). To determine whether p53 is involved in mediating senescence in this system, cultures were infected with short hairpin (sh) constructs specific for p53 with and without Creexpressing retrovirus. The effectiveness of the sh p53 construct has been demonstrated previously (R. Dickens and S.W. Lowe, in prep.; J. Silva and G. Hannon, in prep.); in addition, Western analyses indicate that p53 levels are reduced in primary keratinocytes infected with the sh p53 construct (Supplementary Fig. 2A). Strikingly, knock-down of p53 prevented senescence induced by p63 ablation as seen by normal morphology and the low percentage of SA- $\beta$-gal-positive cells (Fig. 7C). In contrast, 
A

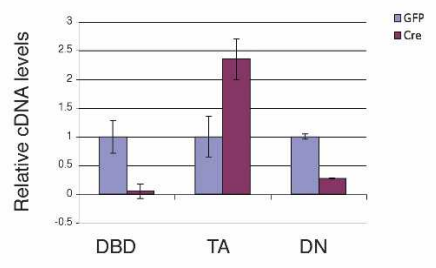

C

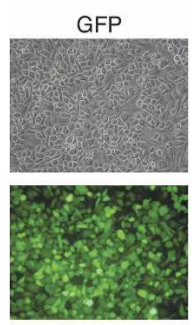

Cre +

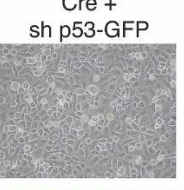

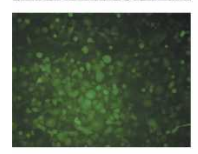
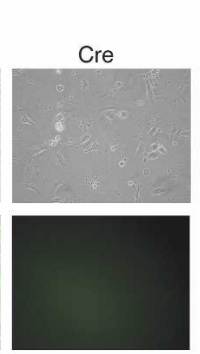

Cre +

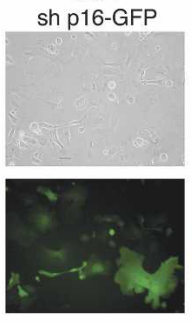

Cre + DNp63 $\alpha$-GFP
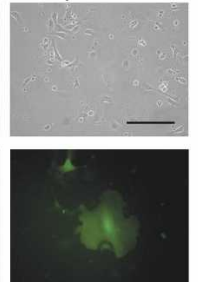

Cre +

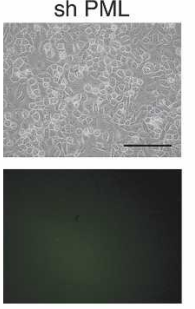

B
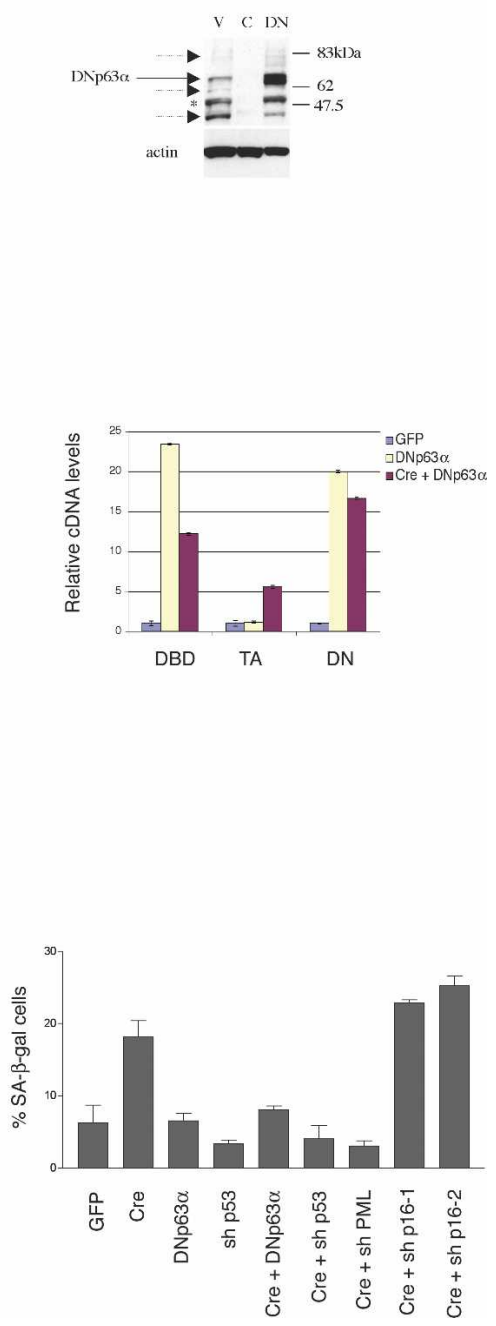

Figure 7. Senescence in p63-ablated keratinocytes is prevented by knock-down of p53 and PML, but not by $16^{\text {INK4a }}$ knock-down or ectopic DNp63a overexpression. (A) Realtime PCR analysis for the DBD, TA, and Nterminal truncated (DN) transcripts in response to Cre-mediated ablation in primary keratinocytes. $(B)$ Western blot analysis for p63 in GFP-infected (V), Cre-infected $(\mathrm{C})$, or DNp63 $\alpha$-infected (DN) keratinocytes, showing that the DNp63 $\alpha$ isoform (arrow) and other putative p63 isoforms (dashed arrows) are efficiently ablated in Cre-infected cultures. Asterisk denotes nonspecific band. (C, top right) Real-time PCR analysis for transcripts encoding different p63 isoform subtypes in keratinocytes infected with GFP, DNp63 $\alpha$, or Cre + DNp63 $\alpha$. (Left) Phenotypic and fluorescent analyses of primary keratinocyte cultures infected with GFP- or Cre-expressing vectors, or with Cre in combination with $\mathrm{DNp} 63 \alpha$, or with Cre in combination with short hairpins specific for $\mathrm{p} 53, \mathrm{p} 16^{\mathrm{INK} 4 \mathrm{a}}$ or PML. The proliferation defect was prevented in cultures treated with sh p53 and sh PML, but not sh p16 or DNp63 $\alpha$. (Bottom right) Cultures were assayed for SA- $\beta$-gal activity following infection, and the percentage of positive cells was quantitated. Bars, 100 $\mu \mathrm{m}$. parallel cultures infected with retroviral constructs specific for $\mathrm{p} 16^{\mathrm{INK} 4 \mathrm{a}}$ along with Cre became senescent, indicating that $\mathrm{p} 16^{\mathrm{INK} 4 \mathrm{a}}$ deficiency is not sufficient for preventing the senescent phenotype mediated by p63 loss (Fig. 7C), even though the two different sh p16 $6^{\mathrm{INK} 4 \mathrm{a}}$ constructs used were able to efficiently reduce p16 $6^{\mathrm{INK} 4 a}$ levels (Supplementary Fig. 2B). In contrast, similar experiments using shRNA constructs specific for PML dramatically prevented senescence caused by $p 63$ disruption (Fig. 7C). These experiments indicate that ablation of p63 in primary keratinocytes grown in culture mediates a program of cellular senescence that involves p53and PML-mediated pathways.

\section{Discussion}

This study provides direct in vivo evidence linking the p53-related protein p63 to both cellular senescence and aging. Cellular senescence in vitro has been characterized functionally by decreased proliferation, morphologically by microscopic examination of cell shape, and bio- chemically by the expression of specific markers. p63 deficiency induces senescence in vivo and in vitro, as measured by each of these criteria; p63 deficiency causes decreased proliferation, altered morphology, enhanced SA- $\beta$-gal activity, and increased expression of $\mathrm{p} 16^{\mathrm{INK} 4 \mathrm{a}}$ and PML (Pearson et al. 2000; Campisi 2001). Although increased p53 expression is a well-characterized regulator of senescence, we did not detect increased p53 expression when senescence was induced by p63 deficiency in vitro or in vivo, and senescence was observed in tissues deficient for both p63 and p53, suggesting that p63 functions either downstream or in a parallel pathway to p53 in the senescent process. Indeed, DNA-damaging agents known to induce cellular senescence and to promote accelerating aging features of the skin, such as UV irradiation, enhance p53 activity while concomitantly down-regulating DNp63 $\alpha$ (Liefer et al. 2000). Furthermore, the finding that p53 directly binds DNp63 and targets it for caspase-dependent degradation (Ratovitski et al. 2001), as well as the similar decrease in life span and overlapping phenotypes of mice with enhanced p53 (Tyner et al. 2002) and those with compromised p63 (this 
study), supports a model in which p63 is directly downstream of p53. Although senescence induced by p63 deficiency was p53-independent in vivo, senescence was prevented when p63 and p53 were simultaneously ablated in primary keratinocytes. The different requirement for p53 in senescence in vitro and in vivo could be due to alterations imposed by cell culture. Alternatively, distinct cellular responses such as apoptosis or cell adhesion might be specifically affected by depletion of p 53 or PML, enhancing overall cell survival. More intriguingly, the different requirements for p53 in distinct experimental settings could be the consequence of an alteration in the ratio of different p63 isoforms. Indeed, p53 is dispensable for senescence in mice with germline p63 deficiency that do not progress past the primitive ectodermal stage. In contrast, primary keratinocytes were harvested from mature skin that has already completed morphogenesis and after a complex pattern of p63 expression has already been established; in this setting, senescence induced by p63 deficiency is dependent on p53. Thus, the different requirements for p53 may be due to interactions between p53-related proteins that differ in undifferentiated versus mature tissue.

Our data describe a mechanism of senescence induction that involves increased expression of $\mathrm{p} 16^{\mathrm{INK} 4 \mathrm{a}}$ and PML, the first data suggesting a link between these proteins and p63. Not only are these key markers of the senescent pathway, but both $\mathrm{p} 16^{\mathrm{INK} 4 \mathrm{a}}$ and PML are also potent inducers of senescence, with overexpression of PML inducing a p53-dependent senescence pathway (Dai and Enders 2000; Ferbeyre et al. 2000; Pearson et al. 2000). Intriguingly, knock-down of PML, but not $\mathrm{p} 16^{\mathrm{INK} 4 \mathrm{a}}$, was sufficient to suppress p63-deficiency-induced senescence in primary keratinocytes. Recent reports, however, also implicate PML as a direct target of p53 (de Stanchina et al. 2004), and in maintaining the stability of p53 family members p53 and p 73 (Bernardi et al. 2004; Bernassola et al. 2004). Decreased levels of p63 have been associated with both withdrawal from the cell cycle and increased expression of cell cycle inhibitors such as p21 (Westfall et al. 2003; Koster and Roop 2004). Whether p63 can function as a direct repressor of PML or $\mathrm{p} 16^{\mathrm{INK} 4 \mathrm{a}}$, as has been shown for $\mathrm{p} 21$, will require further investigation. However, p63's ability to modulate genes involved in renewal, proliferation, and differentiation is consistent with our findings that compromised p63 causes growth arrest that contributes to the inability to replenish epithelial tissues, hence leading to accelerated aging. Furthermore, this check on proliferation may provide a mechanism for tumor protection, a hypothesis consistent with the low incidence of tumors in $p 63$ heterozygous mutant mice (W.M. Keyes and A.A. Mills, unpubl.).

p63 deficiency in vivo results in many features of agerelated decline. In elderly patients and in several mouse models of aging, phenotypic features of accelerated aging in vivo include: decreased life span, reduced body weight, lordokyphosis (curvature of the spine), decreased bone density, decreased organ mass, cellular senescence, alopecia, increased skin ulcerations and atrophy, de- creased dermal and adipose thickness, and sebaceous gland hyperplasia (de Boer et al. 2002; Tyner et al. 2002; Cao et al. 2003; Hasty et al. 2003; Maier et al. 2004; Sun et al. 2004; Trifunovic et al. 2004)-many of which we have described herein in mice with compromised p63.

Although the $p 63$ conditional model disrupts $p 63$ in specific tissues such as stratified epithelia, age-related decline was noted globally. It is formally possible that the observed age-related pathology is caused by Cre-mediated disruption of $p 63$ in nonepithelial tissues that is occurring at levels below that detectable by the PCR assay used. It is more plausible, however, that the global aging phenotypes are either direct consequences of p63 deficiency in K5-expressing tissues such as stratified epithelia, or are secondary effects caused by altered tissue homeostasis mediated by p63 loss in specific tissues in which p63 is not compromised. While previous studies have demonstrated that senescence can be communicated from one cell type to another (Krtolica et al. 2001), future studies will be required to determine whether senescence induced by tissue-specific p63 loss causes accelerated aging in tissues.

Several models of aging directly link C-terminal fragments of p53 to accelerated aging (Tyner et al. 2002; Maier et al. 2004; Campisi 2005). As the two models used in the current study involve either germline reduction/deficiency or somatic ablation of all p63 isoforms (Mills et al. 1999, 2002), whether distinct p63 proteins can function in a manner analogous to truncated p53 isoforms or whether specific p63 isoforms regulate cellular senescence and aging remain intriguing possibilities. Indeed, the recent report that p53 also encodes multiple isoforms adds an additional layer of complexity to the role of p53 family members in senescence and aging (Bourdon et al. 2005).

The predominant isoform expressed in mature proliferating epithelia is $\mathrm{DNp} 63 \alpha$, which also correlates with proliferating cells in both mouse and zebrafish epidermal development (Yang et al. 1998; Lee and Kimelman 2002). $\mathrm{DNp} 63 \alpha$ promotes proliferation of basal keratinocytes by acting as a transcriptional repressor of cell cycle inhibitors such as p21 and 14-3-3 (Westfall et al. 2003). During cell cycle withdrawal and induction of differentiation, this isoform is decreased, freeing up the cell cycle inhibitors. DNp63 proteins are also increased in multiple tumor types (Parsa et al. 1999; Hibi et al. 2000), and overexpression induces $\beta$-catenin nuclear accumulation and proliferation (Patturajan et al. 2002), consistent with the role of DNp63 in maintaining proliferation of stratified epithelia. This is in agreement with the findings from both our models that show depletion of the DNp63 $\alpha$ isoform and concomitant loss of proliferation. Expression of DNp63 $\alpha$ was not capable of preventing p63-deficiency-induced senescence, suggesting that loss of other p63 isoforms, or combinations thereof, mediates senescence when depleted. TA- and DN-p63 isoforms are capable of exerting opposing effects on multiple genes (Wu et al. 2003), and the fact that DNp63 isoforms can inhibit transactivation of TAp63 isoforms, the ratio of different p63 isoforms, as well as their interactions with 
other p53 family members, is likely to affect cellular senescence and hence the aging processes (Maier et al. 2004). Indeed, our finding that p53 deficiency abrogates senescence induced by p63 loss in vitro indicates that interactions between p53-related proteins functionally modulate the senescent process. Further studies using isoform-specific mouse models and/or RNAi technology will be useful for determining which p63 isoform(s) normally regulate the cellular senescence.

Most importantly, our model directly links senescence with accelerated aging in vivo. The aging process has been attributed to a decrease in tissue renewal capability, possibly by affecting progenitor or stem cell populations (Park et al. 2004; Sharpless and DePinho 2004; Campisi 2005). The developing epidermis has been described as progenitor-like, and p63 is a key mediator in skin morphogenesis and maintenance, affecting both the proliferating keratinocytes and the epidermal stem cells. Here we describe, in progenitor or stem cell-like populations, increased expression of $\mathrm{p} 16^{\mathrm{INK} 4 \mathrm{a}}$ and SA- $\beta$-gal activity, both of which are known to accumulate during normal aging. Indeed, $\mathrm{p} 16^{\mathrm{INK} 4 \mathrm{a}}$ has recently been suggested to be both a biomarker and an effector of the aging process (Krishnamurthy et al. 2004). The observation that mice with compromised p63 levels are not tumor prone (W.M. Keyes and A.A. Mills, unpubl.) but age prematurely, as in the case of $p 53^{+/ \mathrm{m}}$ mice (Tyner et al. 2002), reinforces the theory that tumor-suppressive mechanisms such as apoptosis and senescence are beneficial in early life, but may contribute to the aging process (Campisi 2001, 2005). Together, our data uncover two new mechanisms regulated by p63: senescence regulated by $\mathrm{p} 16^{\mathrm{INK} 4 \mathrm{a}}$ and $\mathrm{PML}$, and aging regulated by senescence in proliferating/stem cells, and strengthens previous reports linking the two processes.

\section{Materials and methods}

\section{Mouse strains and genotyping}

$p 63^{+/-}$mice harboring the $p 63^{\text {Brdm2 }}$ allele were used in this study (Mills et al. 1999). A tumor/aging study was conducted in which $p 63^{+/-}(n=104)$ and $p 63^{+/+}(n=74)$ were fed ad libitum and monitored for malignancies and general health over a 2.2-yr period. Statistical analysis of survival was performed using the log-rank test of the Kaplan-Meier format. The p63 conditional model was generated by crossing $p 63^{\text {flox } / \text { flox }}$ mice (Mills et al. 2002) to $p 63^{\text {Brdm2/+ }}$; K5CrePR1 mice (Zhou et al. 2002). For embryonic ablation, pregnant females were injected at E8.5-E10.5 with a single intraperitoneal injection of mifepristone (RU486; $500 \mu \mathrm{g} / \mathrm{mL}$ in sesame oil), followed by implantation of a progesterone pellet to maintain pregnancy. Newborn or adult /ranging from 8 to $24 \mathrm{~mol} p 63^{\text {flox/flox }}$ K5CrePR1 or p63 $3^{\text {flox } / \text { Brdm2 }}$; K5CrePR1 mice were analyzed following single or sequential intraperitoneal injections of mifepristone. Skin biopsies were taken 2-7 d post-injection. Genomic DNA from tail tip biopsies was digested with BamHI and subjected to Southern analysis to identify the wild-type $p 63$ locus, as well as the $p 63^{\text {Brdm2 }}$ and p63 flox alleles, as described previously (Mills et al. 1999, 2002). PCR was performed with $10 \mathrm{ng}$ of genomic DNA with a MasterCycler gradient thermocycler (Eppendorf) using a $94^{\circ} \mathrm{C}$ dena- turation step for $3 \mathrm{~min}$, followed by 40 cycles of $94^{\circ} \mathrm{C}, 55^{\circ} \mathrm{C}$, and $72^{\circ} \mathrm{C}$ for 1 min each. Reaction products were resolved on $2 \%-$ $4 \%$ agarose gels. The following primers were used to identify distinct $p 63$ alleles: $p 63^{\text {flox }}$ FWD, 5'-AAGTGGCAGTGAG CAGAAC-3'; $p 63^{\text {flox }}$ REV, $5^{\prime}$-ACAATTCCAGTCAAACATCA A-3'; ${ }^{\prime} 63^{\text {Brdm3 }}$ FWD, 5'-CAGAGGAGGCAACACAGGATA GA-3'; $p 63^{\text {Brdm3 }} \mathrm{REV}, 5^{\prime}$-CCGGGGGATCCGAATTCATCGA3 '. The K5CrePR1 transgene and $\beta$-actin were detected with the following primers: Cre FWD, 5' -CGGTCGATGCAACGAGTG3'; Cre REV, 5'-CCACCGTCAGTACGTGAG-3'; $\beta$-actin FWD, $5^{\prime}$-TGGAATCCTGTGGCATCCATGAAAC- $3^{\prime} ; \beta$-actin REV, 5'-TAAAACGCAGCTCAGTAACAGTCCG-3'

\section{RT-PCR and real-time PCR analysis}

Total RNA was isolated from frozen tissues or cells using Trizol reagent. A Tissue-Tek homogenizer was used in the case of tissue. RT-PCR was performed on $0.5 \mu \mathrm{g}$ of total RNA using a Superscript first-strand cDNA synthesis kit (Invitrogen). Realtime PCR was performed according to the manufacturers' specifications using a Peltier Thermal cycler (MJ Research) and a SYBR Green PCR kit (Applied Biosystems). Samples were analyzed in triplicate for at least two separate runs, and were normalized to $\beta$-actin for each reaction. The following primers were used: $\mathrm{q} \beta$-actin FWD, $5^{\prime}$-GATCTGGCACCACACCTTCT3'; q $\beta$-actin REV, 5'-GGGGTGTTGAAGGTCTCAAA-3'; qp63 DBD FWD, 5'-TTATGAGCCACCACAGGTT-3'; qp63 DBD REV, 5'-ACGCAGCTGCTGTTACACAT-3'; qTAp63 FWD, 5'CCAGAGGTCTTCCAGCATA-3'; qTAp63 REV, 5'-TTTCG GAAGGTTCATCCAC-3'; qDNp63 FWD, 5'-CTGGAAAAC AATGCCCAGAC-3'; qDNp63 REV, 5'-GAGGAGCCGTTCT GAATCTG-3'; qp16 FWD, 5'-GTCACACGACTGGGCGATT3'; qp16 REV, 5'-CATGCTGCTCCAGATGGCT-3'; qPML FWD, 5' -AGCAGGAGGCTTCTCAGACAG-3'; qPML REV, 5' CTTGATGATCTTCCTGGAAGCA-3'.

\section{Culture and infection of primary keratinocytes}

Primary keratinocyte cultures were established from 1-2-d-old wild-type or $p 63^{\text {flox } / \text { flox }}$ mice essentially as previously described (Lin and Lowe 2001). Retrovirus was produced by transiently transfecting the Phoenix ecotropic packaging cell line (G. Nolan, Stanford University, Stanford, CA) with the following constructs: pBABE-Cre, pBABE-GFP, MSCV-PIG (Hemann et al. 2003), MSCV DNp63 $\alpha$ cDNA-GFP, sh p53 1224 (R. Dickens and S.W. Lowe, in prep.; J. Silva and G. Hannon, in prep.), sh p16 82.2, sh p16 117-11, and sh PML (de Stanchina et al. 2004). Cultures were maintained in keratinocyte media prior to virus collection. Keratinocyte infections were carried out 72-96 h prior to assaying for endogenous SA- $\beta$-gal activity (Dimri et al. 1995). For experiments involving coculture of Cre with retroviral short hairpin or DNp63 $\alpha$ constructs, cultures were drugselected in $1 \mu \mathrm{g} / \mathrm{mL}$ puromycin $48-72 \mathrm{~h}$ after infection and maintained for up to another $6 \mathrm{~d}$ before analysis.

Representative counts for SA- $\beta$-gal in vector- and Cre-infected keratinocytes are shown from one of five separate experiments, with the percentage of positive cells counted in triplicate from a total of 200 cells for each count.

\section{Histological, immunofluorescent, and Western analyses}

For proliferation analyses, pregnant female mice were injected with BrdU (Zymed) $1 \mathrm{~h}$ prior to tissue harvest. Tissues were processed for paraffin embedding and hematoxylin and eosin $(\mathrm{H} \& \mathrm{E})$ staining. Immunostaining studies were performed using 
standard procedures with the following primary antibodies: anti-PML (monoclonal 36-1-104; 1:200) (de Stanchina et al. 2004), anti-BrdU (Accurate Chemical and Scientific Corporation; 1:200), anti-K14-FITC (Covance; 1:1000), anti-Keratin 1,10,11 (RDI; 1:200), anti-p63 (H137; Santa Cruz; 1:200), and anti-p16 ${ }^{\text {INK4a }}$ (M156; Santa Cruz; 1:200). Secondary antibodies were goat-anti-rabbit-HRP (Pierce; 1:2000), goat-anti-mouse Alexa fluor 594 (Molecular probes, 1:2000), and goat-anti-rabbit Alexa fluor 488 (Molecular Probes; 1:2000). Proliferation was assessed by immunofluorescence, counting the total number of positive cells in 20 fields of view from two mice of each genotype. SA- $\beta$-gal activity was detected in frozen sections as described previously (Dimri et al. 1995). Whole-mount embryo SA- $\beta$-gal was detected similarly following overnight fixation and incubation with X-gal for 4-6 h. Skin biopsies were harvested and subjected to histological staining with $H \& E$.

Immunoblotting was performed on dorsal back skin samples solubilized in Laemmli buffer. Samples of 10-20 $\mu \mathrm{g}$ of protein (Bio-Rad protein assay) were analyzed using standard procedures, with antibodies for p63 (monoclonal 4A4; Santa Cruz; $1: 800)$, anti-PML as above (1:1000), and p53 (505; Novacastra; $1: 500)$.

\section{Acknowledgments}

We thank Alex Gann for critical reading of the manuscript; Darren Burgess for retroviral shRNA constructs specific for mouse p16 ${ }^{\text {INK4a }}$ hairpins; Sihem Cheloufi and Lisa Bianco for animal procedures; and Mike Hemann, Yvette Seger, and Ross Dickens for helpful discussions. This work was supported by National Institutes of Health grant AR47898.

\section{References}

Bernardi, R., Scaglioni, P.P., Bergmann, S., Horn, H.F., Vousden, K.H., and Pandolfi, P.P. 2004. PML regulates p53 stability by sequestering Mdm2 to the nucleolus. Nat. Cell Biol. 6: 665672.

Bernassola, F., Salomoni, P., Oberst, A., Di Como, C.J., Pagano, M., Melino, G., and Pandolfi, P.P. 2004. Ubiquitin-dependent degradation of p73 is inhibited by PML. J. Exp. Med. 199: $1545-1557$.

Bourdon, J.-C., Fernandes, K., Murray-Zmijewski, F., Liu, G., Diot, A., Xirodimas, D.P., Saville, M.K., and Lane, D.P. 2005. p53 isoforms can regulate p53 transcriptional activity. Genes \& Dev. (in press).

Campisi, J. 2001. Cellular senescence as a tumor-suppressor mechanism. Trends Cell Biol. 11: S27-S31.

. 2005. Senescent cells, tumor suppression, and organismal aging: Good citizens, bad neighbors. Cell 120: 513-522.

Cao, L., Li, W., Kim, S., Brodie, S.G., and Deng, C.X. 2003. Senescence, aging, and malignant transformation mediated by p53 in mice lacking the Brcal full-length isoform. Genes \& Dev. 17: 201-213.

Carraresi, L., Tripodi, S.A., Mulder, L.C., Bertini, S., Nuti, S., Schuerfeld, K., Cintorino, M., Bensi, G., Rossini, M., and Mora, M. 2001. Thymic hyperplasia and lung carcinomas in a line of mice transgenic for keratin 5-driven HPV16 E6/E7 oncogenes. Oncogene 20: 8148-8153.

Dai, C.Y. and Enders, G.H. 2000. p16 $6^{\mathrm{INK} 4 \mathrm{a}}$ can initiate an autonomous senescence program. Oncogene 19: 1613-1622.

de Boer, J., Andressoo, J.O., de Wit, J., Huijmans, J., Beems, R.B., van Steeg, H., Weeda, G., van der Horst, G.T., van Leeuwen, W., Themmen, A.P., et al. 2002. Premature aging in mice deficient in DNA repair and transcription. Science 296: 1276-1279.

de Stanchina, E., Querido, E., Narita, M., Davuluri, R.V., Pandolfi, P.P., Ferbeyre, G., and Lowe, S.W. 2004. PML is a direct p53 target that modulates p53 effector functions. Mol. Cell 13: $523-535$.

Dimri, G.P., Lee, X., Basile, G., Acosta, M., Scott, G., Roskelley, C., Medrano, E.E., Linskens, M., Rubelj, I., Pereira-Smith, O., et al. 1995. A biomarker that identifies senescent human cells in culture and in aging skin in vivo. Proc. Natl. Acad. Sci. 92: 9363-9367.

Ferbeyre, G., de Stanchina, E., Querido, E., Baptiste, N., Prives, C., and Lowe, S.W. 2000. PML is induced by oncogenic ras and promotes premature senescence. Genes \& Dev. 14: 2015-2027.

Fuchs, E. and Raghavan, S. 2002. Getting under the skin of epidermal morphogenesis. Nat. Rev. Genet. 3: 199-209.

Hasty, P., Campisi, J., Hoeijmakers, J., van Steeg, H., and Vijg, J. 2003. Aging and genome maintenance: Lessons from the mouse? Science 299: 1355-1359.

Hayflick, L. 1965. The limited in vitro lifetime of human diploid cell strains. Exp. Cell Res. 37: 614-636.

Hemann, M.T., Fridman, J.S., Zilfou, J.T., Hernando, E., Paddison, P.J., Cordon-Cardo, C., Hannon, G.J., and Lowe, S.W. 2003. An epi-allelic series of p53 hypomorphs created by stable RNAi produces distinct tumor phenotypes in vivo. Nat. Genet. 33: 396-400.

Hibi, K., Trink, B., Patturajan, M., Westra, W.H., Caballero, O.L., Hill, D.E., Ratovitski, E.A., Jen, J., and Sidransky, D. 2000. AIS is an oncogene amplified in squamous cell carcinoma. Proc. Natl. Acad. Sci. 97: 5462-5467.

Hirako, Y., Yamakawa, H., Tsujimura, Y., Nishizawa, Y., Okumura, M., Usukura, J., Matsumoto, H., Jackson, K.W., Owaribe, K., and Ohara, O. 2003. Characterization of mammalian synemin, an intermediate filament protein present in all four classes of muscle cells and some neuroglial cells: Co-localization and interaction with type III intermediate filament proteins and keratins. Cell Tissue Res. 313: 195207.

Koster, M.I. and Roop, D.R. 2004. The role of p63 in development and differentiation of the epidermis. J. Dermatol. Sci. 34: 3-9.

Koster, M.I., Kim, S., Mills, A.A., DeMayo, F.J., and Roop, D.R. 2004. p63 is the molecular switch for initiation of an epithelial stratification program. Genes \& Dev. 18: 126-131.

Krishnamurthy, J., Torrice, C., Ramsey, M.R., Kovalev, G.I., Al-Regaiey, K., Su, L., and Sharpless, N.E. 2004. Ink4a/Arf expression is a biomarker of aging. J. Clin. Invest. 114: 12991307.

Krtolica, A., Parrinello, S., Lockett, S., Desprez, P.Y., and Campisi, J. 2001. Senescent fibroblasts promote epithelial cell growth and tumorigenesis: A link between cancer and aging. Proc. Natl. Acad. Sci. 98: 12072-12077.

Kurita, T., Mills, A.A., and Cunha, G.R. 2004. Roles of p63 in the diethylstilbestrol-induced cervicovaginal adenosis. Development 131: 1639-1649.

Lee, H. and Kimelman, D. 2002. A dominant-negative form of p63 is required for epidermal proliferation in zebrafish. Dev. Cell 2: 607-616.

Liefer, K.M., Koster, M.I., Wang, X.J., Yang, A., McKeon, F., and Roop, D.R. 2000. Down-regulation of p63 is required for epidermal UV-B-induced apoptosis. Cancer Res. 60: 4016-4020.

Lin, A.W. and Lowe, S.W. 2001. Oncogenic ras activates the ARF-p53 pathway to suppress epithelial cell transformation. Proc. Natl. Acad. Sci. 98: 5025-5030.

Loonstra, A., Vooijs, M., Beverloo, H.B., Allak, B.A., van 
Drunen, E., Kanaar, R., Berns, A., and Jonkers, J. 2001. Growth inhibition and DNA damage induced by Cre recombinase in mammalian cells. Proc. Natl. Acad. Sci. 98: 92099214.

Maier, B., Gluba, W., Bernier, B., Turner, T., Mohammad, K., Guise, T., Sutherland, A., Thorner, M., and Scrable, H. 2004. Modulation of mammalian life span by the short isoform of p53. Genes \& Dev. 18: 306-319.

McKeon, F. 2004. p63 and the epithelial stem cell: More than status quo? Genes \& Dev. 18: 465-469.

Mills, A.A., Zheng, B., Wang, X.J., Vogel, H., Roop, D.R., and Bradley, A. 1999. p63 is a p53 homologue required for limb and epidermal morphogenesis. Nature 398: 708-713.

Mills, A.A., Qi, Y., and Bradley, A. 2002. Conditional inactivation of p63 by Cre-mediated excision. Genesis 32: 138-141.

Narita, M., Nunez, S., Heard, E., Lin, A.W., Hearn, S.A., Spector, D.L., Hannon, G.J., and Lowe, S.W. 2003. Rb-mediated heterochromatin formation and silencing of E2F target genes during cellular senescence. Cell 113: 703-716.

Park, I.K., Morrison, S.J., and Clarke, M.F. 2004. Bmi1, stem cells, and senescence regulation. J. Clin. Invest. 113: 175179.

Parsa, R., Yang, A., McKeon, F., and Green, H. 1999. Association of p63 with proliferative potential in normal and neoplastic human keratinocytes. J. Invest. Dermatol. 113: 1099-1105.

Patturajan, M., Nomoto, S., Sommer, M., Fomenkov, A., Hibi, K., Zangen, R., Poliak, N., Califano, J., Trink, B., Ratovitski, E., et al. 2002. DeltaNp63 induces $\beta$-catenin nuclear accumulation and signaling. Cancer Cell 1: 369-379.

Pearson, M., Carbone, R., Sebastiani, C., Cioce, M., Fagioli, M., Saito, S., Higashimoto, Y., Appella, E., Minucci, S., Pandolfi, P.P., et al. 2000. PML regulates p53 acetylation and premature senescence induced by oncogenic Ras. Nature 406: 207210.

Ratovitski, E.A., Patturajan, M., Hibi, K., Trink, B., Yamaguchi, K., and Sidransky, D. 2001. p53 associates with and targets Delta Np63 into a protein degradation pathway. Proc. Natl. Acad. Sci. 98: 1817-1822.

Rodwell, G.E., Sonu, R., Zahn, J.M., Lund, J., Wilhelmy, J., Wang, L., Xiao, W., Mindrinos, M., Crane, E., Segal, E., et al. 2004. A transcriptional profile of aging in the human kidney. PLOS Biol. 2: e427.

Salomoni, P. and Pandolfi, P.P. 2002. The role of PML in tumor suppression. Cell 108: 165-170.

Schmitt, C.A., Fridman, J.S., Yang, M., Lee, S., Baranov, E., Hoffman, R.M., and Lowe, S.W. 2002. A senescence program controlled by $\mathrm{p} 53$ and $\mathrm{p} 16^{\mathrm{INK} 4 \mathrm{a}}$ contributes to the outcome of cancer therapy. Cell 109: 335-346.

Serrano, M., Lin, A.W., McCurrach, M.E., Beach, D., and Lowe, S.W. 1997. Oncogenic ras provokes premature cell senescence associated with accumulation of p53 and p16 ${ }^{\text {INK4a }}$. Cell 88: 593-602.

Sharpless, N.E. and DePinho, R.A. 2004. Telomeres, stem cells, senescence, and cancer. J. Clin. Invest. 113: 160-168.

Sun, L.Q., Lee, D.W., Zhang, Q., Xiao, W., Raabe, E.H., Meeker, A., Miao, D., Huso, D.L., and Arceci, R.J. 2004. Growth retardation and premature aging phenotypes in mice with disruption of the SNF2-like gene, PASG. Genes \& Dev. 18: $1035-1046$.

Trifunovic, A., Wredenberg, A., Falkenberg, M., Spelbrink, J.N., Rovio, A.T., Bruder, C.E., Bohlooly, Y.M., Gidlof, S., Oldfors, A., Wibom, R., et al. 2004. Premature ageing in mice expressing defective mitochondrial DNA polymerase. Nature 429: 417-423.

Tyner, S.D., Venkatachalam, S., Choi, J., Jones, S., Ghebranious, N., Igelmann, H., Lu, X., Soron, G., Cooper, B., Brayton, C., et al. 2002. p53 mutant mice that display early ageing-associated phenotypes. Nature 415: 45-53.

Westfall, M.D., Mays, D.J., Sniezek, J.C., and Pietenpol, J.A. 2003. The Delta Np63 $\alpha$ phosphoprotein binds the p21 and 14-3-3 $\sigma$ promoters in vivo and has transcriptional repressor activity that is reduced by Hay-Wells syndrome-derived mutations. Mol. Cell. Biol. 23: 2264-2276.

Wu, G., Nomoto, S., Hoque, M.O., Dracheva, T., Osada, M., Lee, C.C., Dong, S.M., Guo, Z., Benoit, N., Cohen, Y., et al. 2003. DeltaNp63 $\alpha$ and $\mathrm{TAp} 63 \alpha$ regulate transcription of genes with distinct biological functions in cancer and development. Cancer Res. 63: 2351-2357.

Yang, A., Kaghad, M., Wang, Y., Gillett, E., Fleming, M.D., Dotsch, V., Andrews, N.C., Caput, D., and McKeon, F. 1998. p63, a p53 homolog at 3q27-29, encodes multiple products with transactivating, death-inducing, and dominant-negative activities. Mol. Cell 2: 305-316.

Yang, A., Schweitzer, R., Sun, D., Kaghad, M., Walker, N., Bronson, R.T., Tabin, C., Sharpe, A., Caput, D., Crum, C., et al. 1999. p63 is essential for regenerative proliferation in limb, craniofacial and epithelial development. Nature 398: 714718.

Zhou, Z., Wang, D., Wang, X.J., and Roop, D.R. 2002. In utero activation of K5.CrePR1 induces gene deletion. Genesis 32: 191-192. 


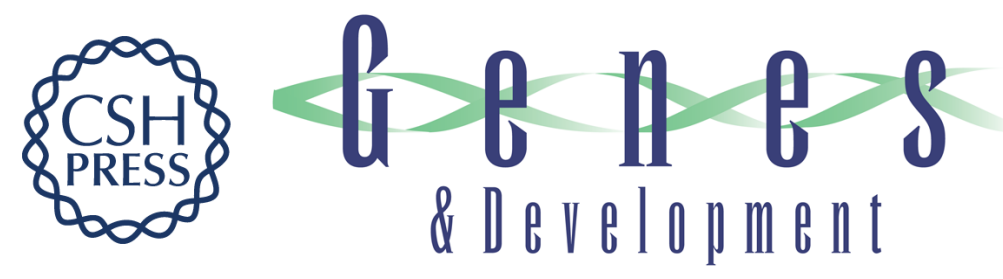

\section{p63 deficiency activates a program of cellular senescence and leads to accelerated aging}

William M. Keyes, Ying Wu, Hannes Vogel, et al.

Genes Dev. 2005, 19:

Access the most recent version at doi:10.1101/gad.342305

Supplemental http://genesdev.cshlp.org/content/suppl/2005/08/18/gad.342305.DC1
Material

References This article cites 49 articles, 19 of which can be accessed free at: http://genesdev.cshlp.org/content/19/17/1986.full.html\#ref-list-1

License

Email Alerting

Receive free email alerts when new articles cite this article - sign up in the box at the top Service right corner of the article or click here.

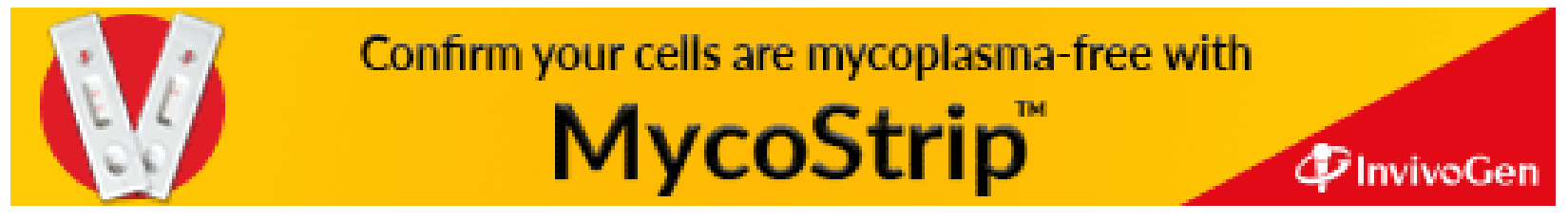

